\title{
Impact of Multiple TCP Connection and Increment of Number of Nodes in Mobile Ad-Hoc Wireless Network
}

\author{
Uttam Khawas \\ M.Tech in CSE \\ Sikkim Manipal Institute of Technology \\ Majhitar, Sikkim India
}

\author{
Kiran Gautam \\ Assistant Professor \\ Sikkim Manipal Institute of Technology \\ Majhitar, Sikkim India
}

\begin{abstract}
Mobile Ad-Hoc Network is an infrastructure less network where the nodes are mobile and each node behaves as a router. The routes may require a multiple hops in the network to reach the destination. There are many routing protocols in MANET that is used to govern the path from the source node to the destination node. This paper focus on the performance of two routing protocol namely DSDV and AODV which are proactive and reactive routing protocols respectively in a MANET using the Transmission Control Protocol NewReno as a transport layer protocol. The number of TCP connection is varied and the performance is evaluated using average throughput, packet delivery ratio and average end to end delay. The same performance metrics are used to see the effect of number of nodes increment in a MANET environment using a TCP connection.
\end{abstract}

\section{Keywords}

MANET, TCP, DSDV, AODV

\section{INTRODUCTION}

Mobile Ad Hoc Networks (MANET) is an autonomous mobile node forming networks which is infrastructure less [14]. Each node behaves as a router and is independent of moving in and out of the temporary Ad-Hoc Network which gives the MANET a dynamic nature. As it is a wireless transmission there are several reliability issues.

Since there are many nodes present in the network the path finding is done using Wireless Ad-Hoc Routing Protocols which are of many types. This paper focuses on some of the routing protocols which are of types: i) Proactive ii) Reactive. Proactive are the routing protocols in which each node maintains tables containing the information about the network. The table is updated which is initiated by a certain node or done in a certain interval of time. Destination Sequenced Distance Vector Routing (DSDV) is an example of proactive routing protocols.

Reactive Routing Protocols are routing protocols in which table are not present containing the information of the network, the path is build when the source node requires to transmit packet. It is the bandwidth efficient protocols as the load for maintaining the table is not present. Ad-Hoc on Demand Distance vector routing protocol is an example of reactive routing protocol.

After finding the path from the source node to the destination node is done than the process to process delivery of the packet is done using the Transport layer protocols

One such protocol is Transmission Control Protocol which has many variant and new Reno is one such variant of TCP.
TCP new reno is the experimental version of TCP reno. It provides the reliability, error control and flow control and delivery of packets in order. TCP is the one of the most used internet protocol and it carries approximately 90 percent of internet traffic [9]. TCP must be independent of the underlying networks [16] i.e. it can be used for both wired and wireless networks but it has been proven that TCP gives good results in wired networks but it does not apply same for the wireless ad-hoc network .One of the main features of TCP is the congestion control mechanisms. In TCP new reno fast retransmit and fast recovery is incorporated.

1. Destination Sequenced Distance Vector Routing Protocols (Proactive)

It is a proactive routing protocol which maintains the table containing the routing information. It is the improved version of the Bellman-Ford algorithm. Each node maintains a table which contains the shortest route and the neighboring node information through which we can reach that particular node. So the availability of routes makes this protocols to setup route with lesser delay .Table also contains the sequence number to remove the stale packets and the duplicate packets and to encounter the count to infinity problems. Tables are updated in a periodic manner or when a node observes that there is significant amount of changes in the network. [5],[9].

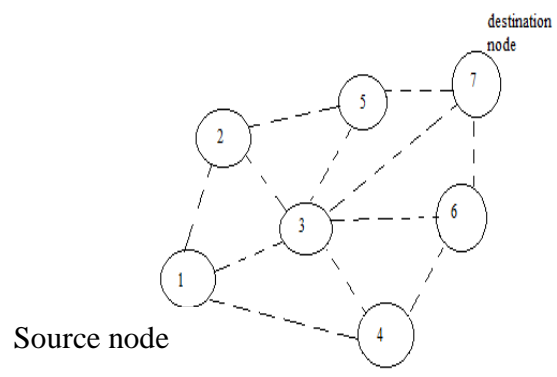

Figure 1: Topology Graph of the network

Table 1: Routing Table for Node 1

\begin{tabular}{|c|c|c|c|}
\hline Destination & Next node & Distance & $\begin{array}{c}\text { Sequence } \\
\text { number }\end{array}$ \\
\hline 2 & 2 & 1 & 22 \\
\hline 3 & 3 & 1 & 26 \\
\hline 4 & 4 & 1 & 30 \\
\hline 5 & 2 & 2 & 34 \\
\hline 6 & 3 & 2 & 38 \\
\hline 7 & 3 & 2 & 42 \\
\hline
\end{tabular}


2. Ad-Hoc On-Demand Distance Vector Routing Protocol It is a reactive routing protocol, which means that whenever a node wants to send some data to another node, at that time they will start searching for the path. It is the extension of the Dynamic Source Routing Protocol. [5, 14, 22]

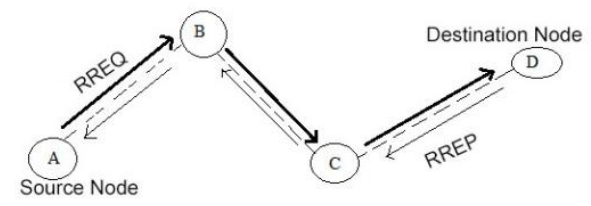

Figure 2: Topology graph of the network

In the above given figure node $\mathrm{A}$ wants to send data to $\mathrm{D}$ then first A sends the Route Request Packet(RREQ) which is broadcasted in the network. Packet format for RREQ:-

<Source address, Source Sequence Number, Broadcast_id, Destination Address, Destination Sequence Number, Hop Count>

The intermediate node discards the packet if the packet has lower sequence number or else it creates a table and updates the information received from the source node and forwards the packet.

Finally when the destination node is reached it creates the table and unicast the Route Reply Packet back tracking the path from which it has received the packet. Then when the information is reached to the source node the source creates the table and now it is ready to send the data packet in the newly created path.

RREQ packet format:-

$<$ Source Address, Destination Address, Destination Sequence, Hop Count, Lifetime>

The Table for Node $\mathrm{C}$ from the above figure after receiving RREP from E:-

Table 2: Intermediate node table node B

\begin{tabular}{|l|l|l|l|l|}
\hline \multicolumn{2}{|l|}{ Destination } & $\begin{array}{l}\text { Next } \\
\text { Node }\end{array}$ & $\begin{array}{l}\text { Hop } \\
\text { Count }\end{array}$ & $\begin{array}{l}\text { Sequence } \\
\text { Number }\end{array}$ \\
\hline $\begin{array}{l}\text { On receiving } \\
\text { RREQ }\end{array}$ & A & A & 1 & 1 \\
\hline $\begin{array}{l}\text { On receiving } \\
\text { RREP }\end{array}$ & D & C & 2 & 120 \\
\hline
\end{tabular}

\section{PERFORMANCE METRICS}

Some of the performances metrics that can be use to evaluate $\mathrm{TCP}$ performance in Ad Hoc routing protocols are:

1. Throughput: it is the number of packets successfully transmitted to the final destination per unit time [9].

2. Packet Delivery Ratio: It is the ratio of actual packet delivered to the total packet sent.

3. Average End to End delay: It is the time taken for the packet to be delivered from the sender node to the receiver node

\section{LITERATURE SURVEY}

Maniah Singh Chaudhaery et al.[5]performed analysis of routing protocols AODV,DSR,DSDV under CBR and TCP traffic sources.The experimental results found that in CBR, if the traffic speed increases the packet loss in DSDV go higher then AODV and DSR. In TCP traffic AODV has much higher packet drop then DSR and DSDV. So it shows that if the speed increases load increases .The output of the simulation shows that reactive routing protocol in CBR traffic performed better than in TCP traffic.

Rachit Jain et al.[4] performed the analysis of the three routing protocols AODV, DSR and DSDV using the two traffic type TCP and CBR in a fixed map size with the pause time $(0,10,20,50,100,200)$. In this simulation the results showed that the overall performance of the on demand routing protocols was better.

Gururaj $\mathrm{H} \mathrm{L}$ et al.[6] performed the comparison of the two TCP variants HS-TCP and Reno in MANET environment. It was found that the congestion window drop rate is less in case of HSTCP when compared to reno. Window size changes more dynamically and sharply in case of HSTCP and leading to larger window size

Samit Rout et al.[16] performed analysis of TCP connection in Mobile Ad-Hoc network considering different network size of $70,50,30$ in an area of $1000 \mathrm{~m}^{*} 1000 \mathrm{~m}$. The routing protocols that were used were AODV, DSDV and DSR. After the simulation results it was found that throughput of the TCP increase slowly with increase of connection till it reaches 20 TCP connections. Packet loss of AODV was found highest, routing overhead of the DSDV was highest and throughput of AODV was better than other two protocols.

\section{SIMULATION SETUP}

Network simulator NS2.35 was used which is available freely and it is a discrete event simulator and it supports wireless adhoc network and TCP. The data extraction from the trace file was done using the awk script and the graph was plotted in GNU plot.

Table 3: Simulation Parameter

\begin{tabular}{|l|l|l|}
\hline \multicolumn{1}{|c|}{ Simulator } & Node density & TCP connection \\
\hline $\begin{array}{l}\text { Simulation } \\
\text { area }\end{array}$ & $1000 \mathrm{~m} * 1000 \mathrm{~m}$ & $1000 \mathrm{~m} * 1000 \mathrm{~m}$ \\
\hline $\begin{array}{l}\text { Number of } \\
\text { mobile nodes }\end{array}$ & $20,30,40,50 \ldots 200$ & 50 \\
\hline Channel type & Wireless & Wireless \\
\hline $\begin{array}{l}\text { Radio } \\
\text { Propagation } \\
\text { Model }\end{array}$ & Two Ray Ground & Two Ray Ground \\
\hline $\begin{array}{l}\text { Network } \\
\text { Interface type }\end{array}$ & Wireless phy & Wireless phy \\
\hline $\begin{array}{l}\text { Link Layer } \\
\text { Type }\end{array}$ & LL & LL \\
\hline Antenna & Omni Antenna & Omni Antenna \\
\hline $\begin{array}{l}\text { Maximum } \\
\text { packet in } \\
\text { queue }\end{array}$ & 50 & 50 \\
\hline $\begin{array}{l}\text { Routing } \\
\text { Protocol }\end{array}$ & DSDV,AODV & DSDV,AODV \\
\hline $\begin{array}{l}\text { Simulation } \\
\text { Time }\end{array}$ & 100 seconds & 100 seconds \\
\hline
\end{tabular}




\begin{tabular}{|l|l|l|}
\hline Speed & Max $10 \mathrm{~m} / \mathrm{s}$ & Max $10 \mathrm{~m} / \mathrm{s}$ \\
\hline $\begin{array}{l}\text { Transmission } \\
\text { Range }\end{array}$ & $250 \mathrm{~m}$ & $250 \mathrm{~m}$ \\
\hline $\begin{array}{l}\text { Number of } \\
\text { TCP } \\
\text { connection }\end{array}$ & 10 Connections & 24 connections \\
\hline
\end{tabular}

Flow diagram for simulation of AODV and DSDV for analyzing the impact of the nodes increment in a MANET environment using the TCP as a transport layer protocol .

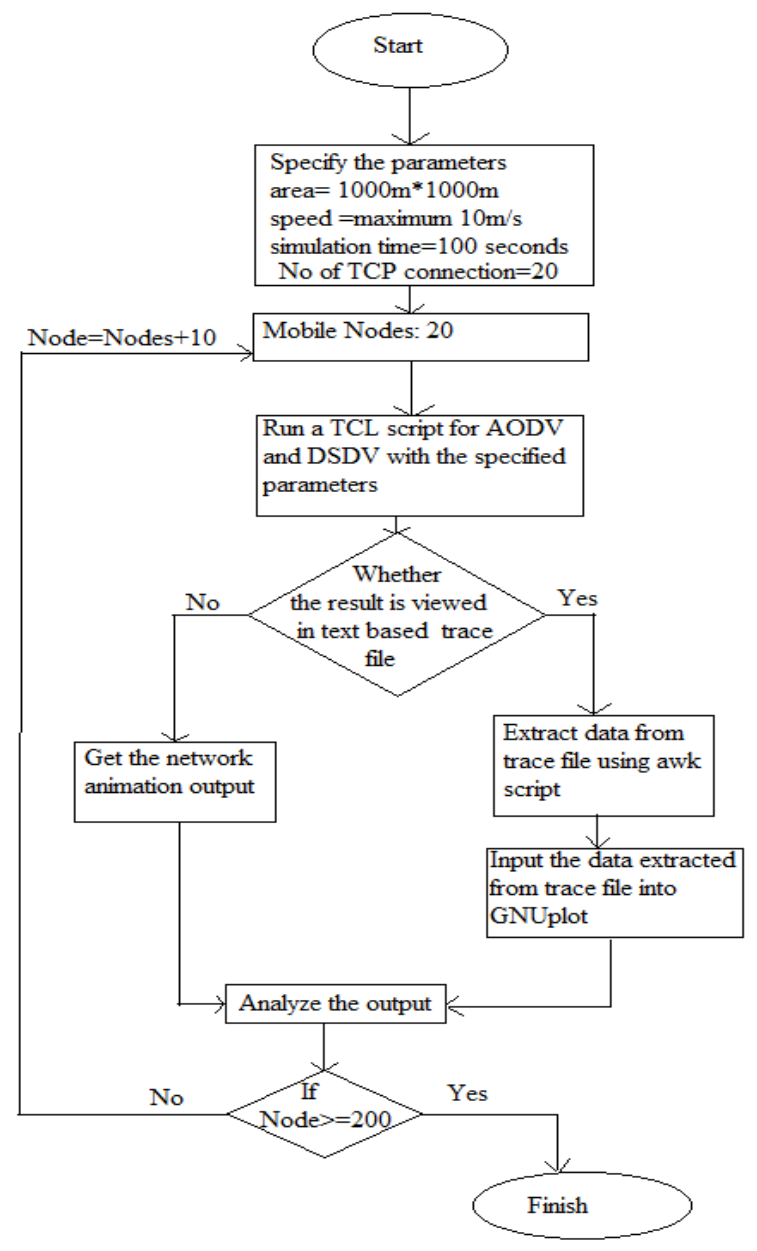

Figure 3: Flow diagram for impact of nodes increment

The same procedure is followed for the impact of the multiple TCP connection in a MANET environment were the mobile nodes are kept constant to 50 and the number of TCP is taken 3 initially and increment 3 number of TCP connection at a time till 24 TCP connection, one TCP connection for each pair.

\section{SIMULATION RESULT AND DISCUSSION}

I. Impact of increment of node density

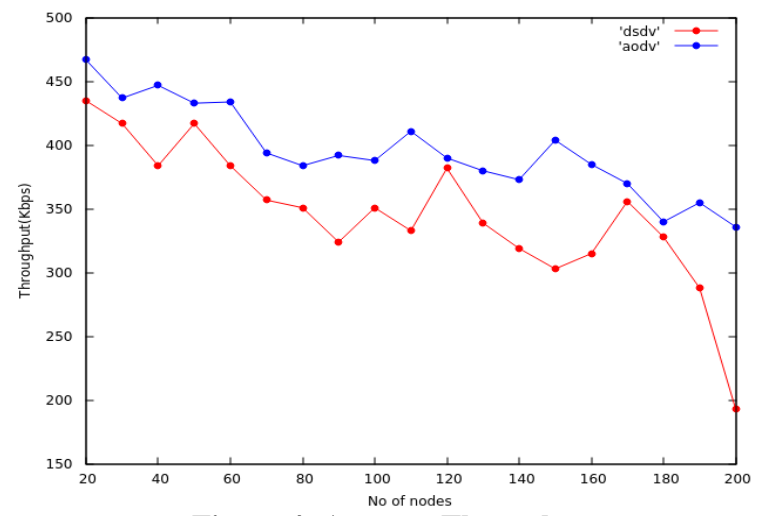

Figure 4: Average Throughput

It can be seen that the throughput decreases as the number of nodes are incremented the throughput is effect more severely for DSDV. The performance of TCP in an MANET environment constantly deteriorates when the node density is increased. One of the main reasons for throughput decrement is the link failure of the mobile nodes.

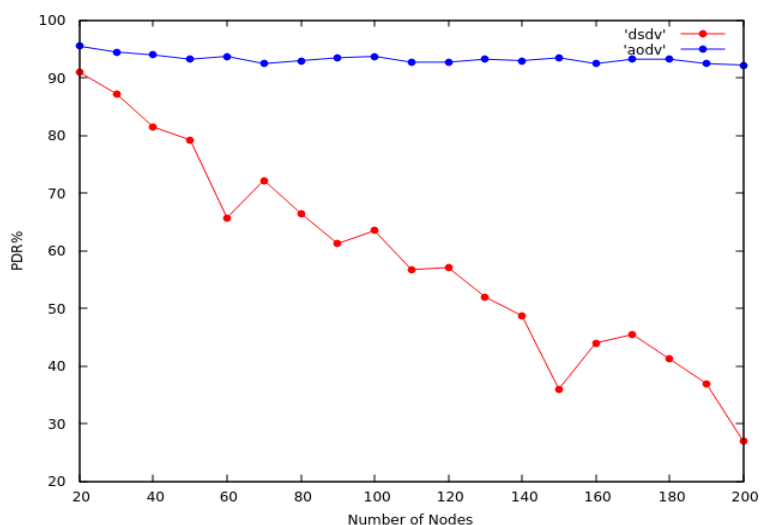

Figure 4.1: Packet Delivery Ratio

DSDV packet delivery ratio is constantly decreasing from $92 \%$ to $27 \%$ when the nodes are incremented, this is due to the fact that the DSDV is a proactive routing protocol, where the routes are already present and when the source nodes want to send data it searches for the route in the table and forwards the packet. Now the nodes are mobile and there is a constant link failure so the route in the table becomes unreachable and many packets become unreachable and the packets get lost in the network. In case of AODV path is build only when required so the packet are lost less in the network.

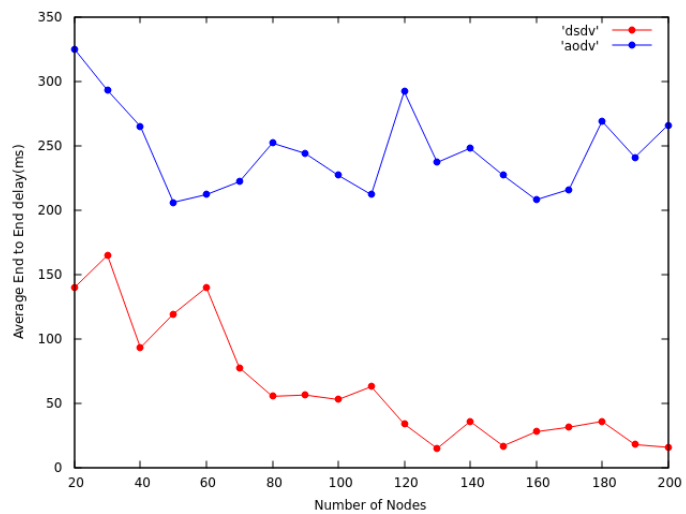

Figure 4.2: Average End to End delay 
AODV has higher average end to end delay as it does not have pre information of the network so the packet takes more time to reach the destination. Whereas the DSDV have a route in its table so it takes much lesser amount of time to reach the destination. The increment of the nodes causes the average end to end delay to decrease slightly as it is due to the path is available easily through multi hop.

II. Impact of number of TCP connection

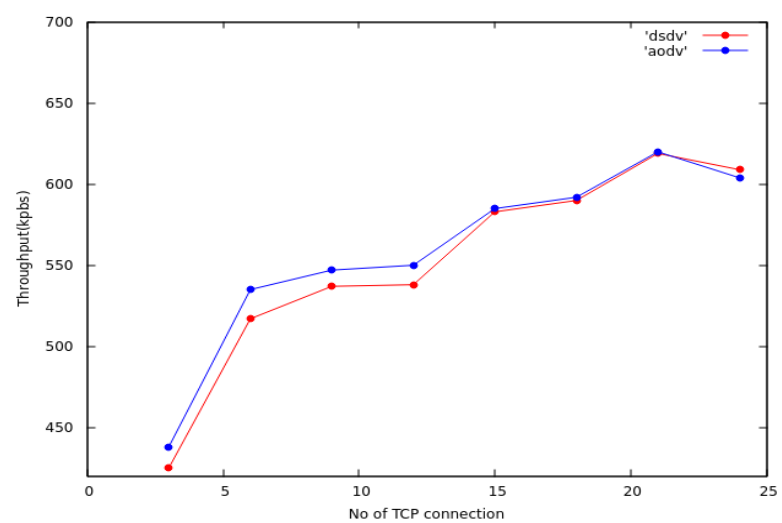

Figure 5: Average Throughput

The throughput is rising as the number of TCP connection is increased till twenty connections after that there is a drop in the throughput.

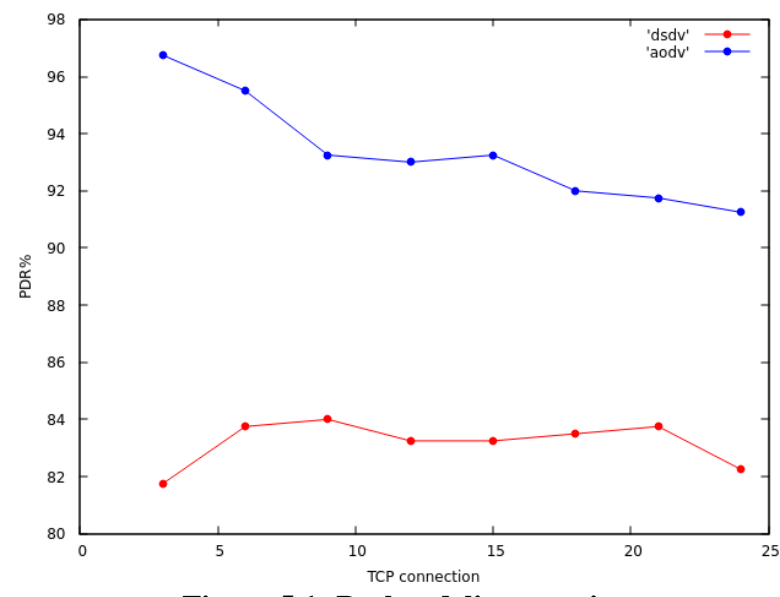

Figure 5.1: Packet delivery ratio

The packet delivery ratio decreases for AODV when the number of TCP connection is increased but the packet delivery ratio of DSDV almost remains constant were the mobile nodes are kept fixed to fifty.

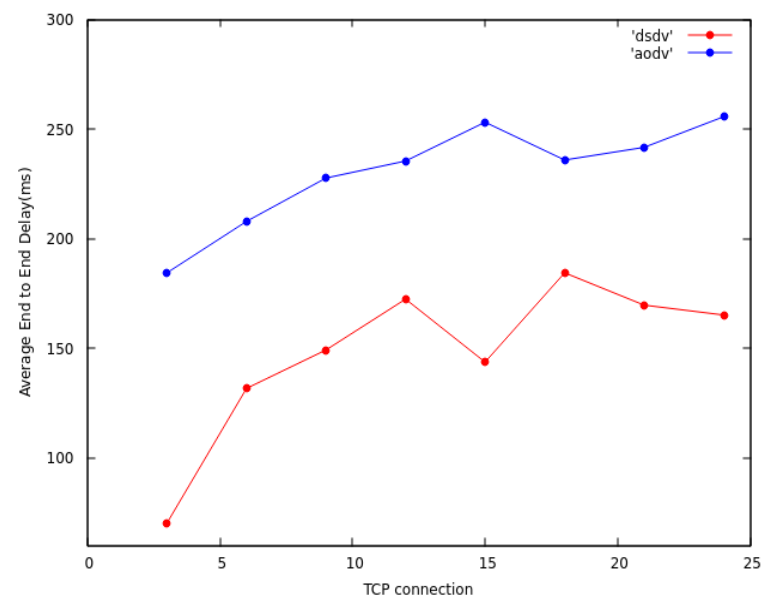

Figure 5.2: Average End to End delay

The average end to end delay for both the protocols increases as the number of TCP connection is increased but the AODV average end to end delay is high due to its reactive nature.

\section{CONCLUSION}

Performance in wireless ad-hoc network topology using TCP continuously degrades when the node is incremented. The throughput of both the DSDV and AODV was decreased from the starting of the simulation from the 20 nodes to 200 nodes. For AODV it was $467 \mathrm{kbps}$ to $336 \mathrm{kbps}$ and for DSDV it decreased from $435 \mathrm{kpbs}$ to $193 \mathrm{kbps}$, so the decrease of the throughput is mainly due to the link failure of the nodes. Packet delivery ratio also decreases for both the protocols but for DSDV it deceases to a great extent, this may be due to the fact that DSDV is a reactive routing protocol, and it maintains a table for the topology in advance. Average end to end delay is higher for AODV than DSDV. Average end to end delay is high because of the link failure, noise and congestion.

We have seen that as the number of TCP connection increases the throughput also increases up to twenty nodes after that the throughput decreases. We can conclude that as the number of TCP connection is increased the number of packets generated is increasing which is exceeding the number of packet lost or dropped in the network but as the number of TCP connection is more than 20 the number of packet lost or dropped in the network is exceeding the number of packets generated in the network that is why the throughput is decreasing. Packet delivery ratio is higher for the AODV than DSDV. DSDV has a lower average end to end delay.

\section{LIMITATION}

All simulation was done only in one variant of the TCP which is TCP new reno which is based on the packet loss probability. The maximum number of nodes that were implemented was 200 .

\section{FUTURE SCOPE}

We could compare the TCP which is simulated that is based on the packet lost probability with queuing delay based TCP variant such as TCP vegas which would help us to compare the nature of the TCP performance.

\section{REFERENCES}

[1] Al Hanbali, Ahmad, Eitan Altman, and Philippe Nain. A survey of TCP over mobile ad hoc networks. Diss. Inria,2004. 
[2] Amjad, Kashif, and Alan J. Stocker. "Impact of node density and mobility on the performance of AODV and DSR in MANETS." Communication Systems Networks and Digital Signal Processing (CSNDSP), 2010 7th International Symposiumon.EEE,2010.

[3] Biradar, S. R., Subir Kumar Sarkar, and C. Puttamadappa. "A Comparison of the TCP VariantsPerformance over different Routing Protocols on Mobile Ad Hoc Networks." International Journal on Computer Science and Engineering 1.2 (2010): 340-344.

[4] Broch, Josh, et al. "A performance comparison of multihop wireless ad hoc network routing protocols." Proceedings of the $4^{\text {th }}$ annual ACM/ IEEE international.

[5] Chaudhary, Manish Singh, and Varsha Singh. "Simulation and analysis of routing protocol under CBR and TCP traffic source." Communication Systems and Network Technologies (CSNT), 2012 International Conference on. IEEE, 2012

[6] C.Shiva Ram Murthy and B.S. Manoj "Ad-Hoc Wireless Network" Pearson.

[7] Devaraj, S. Allwin, R. Helen Vedanayagi Anita, and J. Jennifer Christa. "Comparative analysis of random based mobility models using TCP variant in MANETs." Communication and Network Technologies (ICCNT), 2014 International Conference on. IEEE, 2014.

[8] Dyer, Thomas D., and Rajendra V. Boppana. "A comparison of TCP performance over three routing protocols for mobile ad hoc networks." Proceedings of the 2nd ACM international symposium on Mobile ad hoc networking \& computing.

[9] Gharge, Saylee, and Ajinkya Valanjoo. "Simulation based performance evaluation of TCP variants and routing protocols in Mobile Ad-hoc Networks." Advances in Engineering and Technology Research (ICAETR), 2014 International Conference on. IEEE, 2014.

[10] Gururaj, H. L., and B. Ramesh. "Congestion control for optimizing data transfer rate in mobile Ad-hoc networks using HSTCP." Emerging Research in Electronics, Computer Science and Technology (ICERECT), 2015 International Conference on. IEEE, 2015.

[11] Jain, Rachit, Naresh B. Khairnar, and Laxmi Shrivastava. "Comparitive Study of Three Mobile Ad-hoc Network Routing Protocols Under Different Traffic Source." Communication Systems and Network Technologies (CSNT), 2011 International Conference on. IEEE, 2011.
[12] Larsen, Erlend. "TCP in MANETs-challenges and Solutions." FFI-Rapport-2012/01514 (2012).

[13] Murthy, C. S. R., and B. S. Manoj. "Transport layer and security protocols for ad hoc wireless networks." Ad Hoc Wireless Networks: Architectures and Protocols. Prentice Hall PTR (2004)

[14] Noorani, Razia Nisar. "Comparative analysis of Reactive MANET Routing protocols under the traffic of TCP VEGAS with mobility considerations." Emerging Technologies, 2009. ICET 2009. International Conference on. IEEE, 2009.

[15] Oyedapo, O. J., and D. Ngwenya. "Evaluation of TCPvariants performances in an ad-hoc mobile network." AFRICON 2007. IEEE, 2007.

[16] Rout, Samita, et al. "Impact of multiple TCP connections in mobile ad-hoc network considering different network sizes." Computational Intelligence and Computing Research (ICCIC), 2014 IEEE International Conference on. IEEE, 2014

[17] Sharma, Jitender, and Hardeep Singh. "Analysis of Reno: A TCP Variant." International Journal of Electronics and Communication Engineering (2012).

[18] Singla, Vikas, and Parveen Kakkar. "Traffic Pattern based performance comparison of Reactive and Proactive protocols of Mobile Ad-hoc Networks." International Journal of Computer Applications 5.10 (2010).

[19] Tabash, Ibrahim K., Nesar Ahmad, and Salim Beg. "Performance Evaluation of TCP Reno and Vegas over different routing protocols for MANETs." 2010 IEEE 4th International Symposium on Advanced Networks and Telecommunication Systems. IEEE, 2010.

[20] Tahiliani, Mohit P., K. C. Shet, and T. G. Basavaraju. "Performance evaluation of TCP variants over routing protocols in multi-hop wireless networks." Computer and Communication Technology (ICCCT), 2010 International Conference on. IEEE.

[21] Tomar, Mr Mohit Singh. "Performance Improvment of TCP in Ad hoc Network." Journal of Global Research in Computer Science 3.1 (2012): 17-20.

[22] Tomar, Poonam, and Prashant Panse."A Comprehensive Analysis and Comparison of TCP Tahoe, TCP Reno and TCP Lite." International Journal of Computer Science and Information Technologies (IJCSIT) 2.5 (2011): 2467-2471mputer Science and Engineering 1.2 (2010): 340-344. 